\title{
Stem Cell Transplantation for Motor Neuron Disease: Current Approaches and Future Perspectives
}

\author{
Genevieve Gowing • Clive N. Svendsen
}

Published online: 9 September 2011

(C) The Author(s) 2011. This article is published with open access at Springerlink.com

\begin{abstract}
Motor neuron degeneration leading to muscle atrophy and death is a pathological hallmark of disorders, such as amyotrophic lateral sclerosis or spinal muscular atrophy. No effective treatment is available for these devastating diseases. At present, cell-based therapies targeting motor neuron replacement, support, or as a vehicle for the delivery of neuroprotective molecules are being investigated. Although many challenges and questions remain, the beneficial effects observed following transplantation therapy in animal models of motor neuron disease has sparked hope and a number of clinical trials. Here, we provide a comprehensive review of cell-based therapeutics for motor neuron disorders, with a particular emphasis on amyotrophic lateral sclerosis.
\end{abstract}

Keywords Motor neuron - Amyotrophic lateral sclerosis · Spinal muscular atrophy $\cdot$ Growth factors $\cdot$ Neural stem cell . Transplantation

\section{Introduction to Motor Neuron Diseases}

The selective degeneration of motor neurons (MNs) is a pathological feature of amyotrophic lateral sclerosis (ALS), spinal muscular atrophy (SMA), and other MN diseases.

Electronic supplementary material The online version of this article (doi:10.1007/s13311-011-0068-7) contains supplementary material, which is available to authorized users.

G. Gowing $\cdot$ C. N. Svendsen $(\bowtie)$

Regenerative Medicine Institute,

Department of Biomedical Sciences,

Cedars-Sinai Medical Center,

Los Angeles, CA 90048, USA

e-mail: clive.svendsen@cshs.org
Upper MNs, including giant cells of Betz located in layer 5 of the primary motor cortex and the pyramidal cells of the motor and premotor cortex, control the function of the brainstem, as well as spinal MNs via the corticobulbar and corticospinal tracts, respectively. Lower MNs (somatic) are located in the ventral horn (laminae IX) of the spinal cord and innervate striated muscle of the axial skeleton in both upper and lower limbs. They are the final effectors leading to all voluntary movement. These lower spinal MNs can be divided into classes (alpha, beta, and gamma) and subtypes (fast-twitch fatigable, fast-twitch fatigue resistant, and slow twitch fatigue-resistant) based on the type of muscle fiber they innervate and on the contractile properties of the motor units formed [1]. Although MN cell death (leading to the loss of muscle function) is a common characteristic of ALS and SMA, these disorders affect different populations of $\mathrm{MN}$ across the rostral-caudal axis of the central nervous system (CNS).

\section{ALS}

ALS is an adult-onset disease characterized by the progressive loss of MNs in the cortex, brainstem, and spinal cord leading to the atrophy of skeletal muscle, eventual paralysis and death of patients within 1 to 5 years of disease onset [1-5]. The incidence of ALS is 2 to 3 in 100,000 , and the lifetime risk for ALS is 1 in 2000 individuals, making it the most common $\mathrm{MN}$ disorder $[2,6$, 7]. ALS occurs in both sporadic amyotrophic lateral sclerosis $(90 \%$ of cases) and familial forms (FALS). Predominantly, FALS is inherited in an autosomal dominant manner and 12 to $13 \%$ of these cases are associated with missense mutations in the gene encoding $\mathrm{Cu} / \mathrm{Zn}$ superoxide dismutase $(S O D 1)$ [8]. The recently discovered mutations in the TARDBP and FUS genes account for another $8 \%$ of 
all FALS cases and a small percentage of sporadic amyotrophic lateral sclerosis cases [9]. Interestingly, studies using ALS autopsy samples have shown that motor neurons located in the oculomotor, trochlear, abducens, and Onuf's nuclei are spared in ALS [10-12], whereas other affected motor neuron phenotypes appear to degenerate in specific patterns for each patient [13].

Interestingly, $S O D 1$ gene knockouts did not lead to an ALS phenotype in mice. However, pathological hallmarks associated with motor neuron degeneration in ALS were recapitulated in mutant SOD1 transgenic animal models overexpressing various mutations in this gene [14-16]. The most commonly used animal model is currently based around the missense mutation glycine 93 changed to alanine $(\mathrm{G} 93 \mathrm{~A})$ resulting in the $\mathrm{SOD} 1^{\mathrm{G} 93 \mathrm{~A}}$ transgenic mice. In this model, degeneration initially occurs among fasttwitch fatigable motor units, followed by fast-twitch fatigue resistant, and finally a late stage degeneration of the slow twitch fatigue-resistant subtype of motor neurons [17-20]. However, this progression of motor neuron degeneration has not yet been clearly established in the human disease. Studies in the SOD1 ${ }^{\mathrm{G} 93 \mathrm{~A}}$ mouse model of ALS and in autopsy material from ALS patients has led to the suggestion that degeneration of motor neurons in ALS may start distally at the neuromuscular junction [21, 22]; although there is great interest in this hypothesis, further proof needs to be shown in both animal models and humans. For example, in the rat model of ALS, the early degeneration of the neuromuscular junction was not seen, suggesting that this may be species or model specific [23]. The very recent discovery of new genes associated with FALS have led to the development of novel transgenic animal models, which will undoubtedly prove useful for both uncovering mechanisms of cell death and testing therapeutic strategies, and it has been recently reviewed [24].

Why do motor neurons die selectively in this disease? To date, numerous mechanisms, including oxidative stress, excitotoxicity, impaired neurotrophic support, mitochondrial dysfunction, altered glial function, and more, have been linked to the degeneration of MNs in ALS [25]. Furthermore, certain intrinsic properties, such as their large size (some of the largest neurons in the CNS), long axonal processes, weak calcium-buffering capacities and high metabolic rate may contribute to their susceptibility $[1,26]$. However, recent data suggest that non-neuronal cells also participate in the disease process $[25,27]$, which has major implications for cell therapy approaches as discussed further on in this review. However, despite major scientific progress leading to a better comprehension of the pathological mechanisms associated with the disease, there is still no clear understanding of the causal event(s) initiating MN degeneration in ALS, which is severely affecting drug development.

\section{SMA}

Affecting 1 in 6000 to 10,000 live births, the autosomal recessive disorder SMA is the most common genetic cause of infantile death $[28,29]$. In contrast to ALS, SMA is characterized by the exclusive loss of lower MNs. However, the subtype and pool specific pattern of spinal motor neuron degeneration within the spinal cord in SMA is similar to that observed in ALS [1]. A decreased expression in the survival motor neuron (SMN) protein caused by mutations in the SMN1 gene is responsible for the specific degeneration of spinal $\alpha$-MNs in SMA $[30,31]$. The SMN2 gene is nearly identical to $S M N 1$; however, a translationally silent $\mathrm{C}$ to $\mathrm{T}$ nucleotide conversion in SMN2 results in an alternative splicing event leading to exon 7 exclusion in the majority of the protein product $(\mathrm{SMN} \Delta 7$ ) [32], although a small percent of normal protein is also produced. There are 4 types of SMA based on disease severity and age of onset, which in broad terms are related to SMN2 copy number [33, 34]. Patients with type I SMA are the most severe with an age of onset ranging from 6 to 9 months of age and death occurring by the age of 2 . Type II SMA patients present with an early childhood form of the disease with diagnosis occurring between 6 and 18 months of age and patients generally do not survive past young/middle to adulthood. Type III and IV SMA are less severe with age of onset occurring in late childhood and adulthood, respectively, and although patients are often wheelchair bound and require walking assistance, their lifespan is not affected. In contrast to humans, mice do not possess a copy of the SMN2 gene and knockout of mouse Smn is embryonic lethal [35]. However, insertion of 1 or multiple copies of the SMN2 gene rescues this dramatic embryonic phenotype and provides SMA animal models of varying severity, depending on the number of copies of the SMN2 gene present [29, 36]. Interestingly, as for ALS, pathology at the level of the neuromuscular endplate has been observed in SMA mouse models, but the onset, severity, and features associated with this phenomenon varies among animal models and studies, and has been recently reviewed [37].

\section{Cell-Based Therapies for Motor Neuron Diseases: Replacement or Protection?}

Although MN replacement is the ultimate goal in transplantation therapy for most MN disorders, major hurdles, including cell survival, the generation of functional motor units, and appropriate projection for long distances to connect appropriately with the muscle need to be overcome. The generation and transplantation of support cells aimed at protecting remaining MNs from undergoing degeneration may be more realistic. To date, multiple cell 
types and methods of administration have been investigated in the past and are being investigated now as potential therapeutic candidates for the treatment of MN disease. Table 1 provides a summary of studies completed since 2007 in animal models of motor neuron disease.

\section{Replacing MNs as a Therapeutic Strategy?}

MNs can be obtained from a limited number of sources. Primary MNs can be grown in culture following the isolation of fresh human or rodent fetal tissue [38, 39]. This method is a valuable tool enabling the study of motor neuron development, survival, and pathological mechanisms associated with disease. However, in the context of human grafting, is does not allow for the generation of the substantial number of cells required for transplantation, and tissue sources are scarce. More promising approaches are the differentiation of embryonic, induced pluripotent, or fetal-derived neural stem cells (NSCs) into MNs for transplantation. Embryonic stem (ES) cells are isolated from the inner cell mass of the embryonic blastocyst, they have a large proliferation potential, and they have the capacity of differentiating into cells of ectodermal, mesodermal, or endodermal lineage [40, 41]. Human and rodent ES cells can be efficiently differentiated in vitro to express MN markers, such as ChAT and HB9, and they acquire the appropriate electrophysiological properties of mature $\mathrm{MNs}$ $[42,43]$. Moreover, a small amount of axons extend into the periphery and form neuromuscular junctions following the transplantation of mouse ES cell-derived MNs into the chick embryo [43-45]. Similarly, after intraspinal transplantation, mouse ES cell-derived $\mathrm{MNs}$ were shown to survive, extend axons, form functional motor units, and promote partial recovery from paralysis in a virus-induced rat model of $\mathrm{MN}$ degeneration [46, 47]. In this study, a combination approach, which included the treatment of mouse ES cells with dibutyryl-cAMP to promote MN survival, administration of rolipram, cyclosporine, and glial cell line-derived neurotrophic factor to circumvent myelin repulsion, immune rejection, and promote axonal outgrowth, respectively, contributed to the success of this experimental paradigm. Using this combination paradigm, 35\% of transplanted cells expressed choline acetyl transferase, $5 \%$ of these grafted motor neurons extended axons into ventral roots, and $3 \%$ successfully formed connections at the neuromuscular junction. In another acute model of injury, transplantation of mouse ES cell-derived MNs into transected tibial nerves of adult mice also resulted in the formation of functional neuromuscular synapses by grafted cells [48]. Hence, following transplantation into the parenchyma or peripheral nerve in acute models of injury, some ES cell-derived MNs can form motor units. Nevertheless, axonal extension and the successful generation of neuromuscular junction by grafted ES cell-derived motor neurons in a chronic model of motor neuron disease has not been demonstrated. In fact, although intraspinal grafting of ES cell-derived MNs resulted in a significant improvement in motor behavior in the $\mathrm{SOD} 1^{\mathrm{G} 93 \mathrm{~A}}$ rat model of ALS, a histological analysis revealed a lack of graft survival in endstage animals and no evidence of motor neuron outgrowth to the muscle [49].

This is not surprising as an early in vivo study by Clement et al. [50] revealed that wild-type motor neurons show signs of neuronal distress when surrounded by cells expressing mutant SOD1. Moreover, many studies have shown that multiple factors found in a degenerative microenvironment can kill motors in vitro. Accordingly, the work by Lopez-Gonzalez [49] strongly suggests that longterm exposure to a degenerating or toxic microenvironment can be harmful to otherwise healthy MNs [27, 50-54], and that any functional effects observed were most likely the result of reduced inflammation, trophic factor release from the grafted cells, or the production of protective astrocytes. In a more recent study, following the administration via the cerebrospinal fluid, murine ES-derived NSCs survived, migrated into the parenchyma, generated motor neurons, and improved the phenotype and survival of spinal muscular atrophy mice [55]. Although reduced atrophy of the tibialis anterior was shown, the presence of a functional connection between graft-derived motor neurons and the motor endplate was not investigated. Thus, prior to clinical translation, consistent outgrowth of transplanted motor neurons into animal models of motor neuron disease should be obtained. Moreover, the successful outgrowth of stem cell-derived motor neuron axons and functional connection to the muscle in larger animals, such as the rat, dog, pig, or primate has not yet been shown and is necessary to show feasibility of this approach in humans.

Another potential cell source for generating MNs are fetal-derived NSCs [56]. NSCs self-renew, and are multipotent with the capacity of producing neurons, astrocytes, and oligodendrocytes [57-60]. Efficiency of MN generation from NSC is influenced by cell source, age of tissue at isolation, as well as passage number. In one study, Corti et al. [61] isolated NSCs from mouse embryonic spinal cords, sorted the cells to obtain an aldehyde dehydrogenase (ALDH); side scatter (SSC); subpopulation and differentiated them toward an $\mathrm{MN}$ cell fate by priming with retinoic acid and sonic hedgehog. Administration of primed NSCs via injection into the CSF of neonatal $n m d$ mice, an animal model of spinal muscular dystrophy, resulted in improved phenotype and extended survival. Following transplantation, $8 \%$ of total grafted cells were found to express choline acetyl transferase and $5 \%$ of axons counted in L4 ventral root were found to be of transplant origin. Using a similar strategy, the authors subsequently showed a significant 


\begin{tabular}{|c|c|c|c|c|c|c|c|c|c|c|c|c|}
\hline$\ddot{\mathscr{\Xi}}$ & $\begin{array}{l}\text { 吕 } \\
\stackrel{2}{=}\end{array}$ & $\widetilde{\widetilde{\sigma}}$ & $\stackrel{\sqrt[E]{n}}{\Xi}$ & 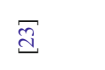 & 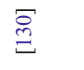 & $\Xi$ & $\stackrel{\infty}{\Xi}$ & 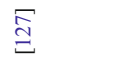 & $\stackrel{\square}{\circ}$ & 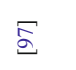 & $\bar{\Omega}$ & $\bar{\Xi}$ \\
\hline 若 & 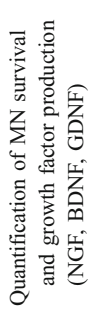 & 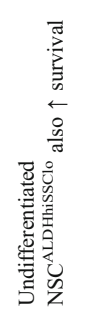 & 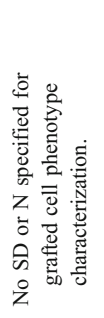 & & 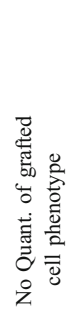 & & & 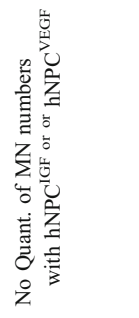 & 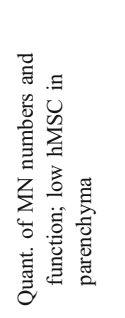 & & & 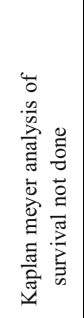 \\
\hline 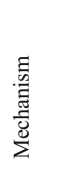 & 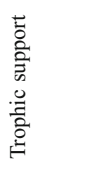 & 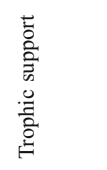 & 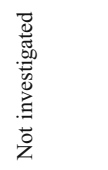 & 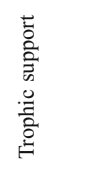 & 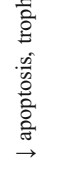 & 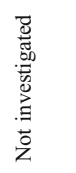 & 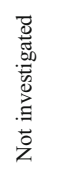 & 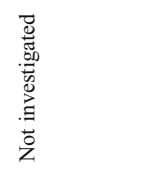 & 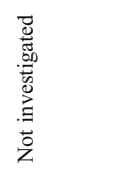 & $\overleftrightarrow{z}$ & 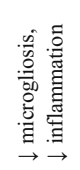 & 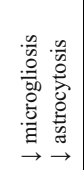 \\
\hline 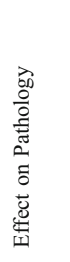 & 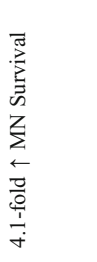 & 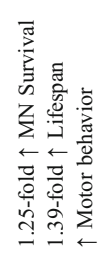 & 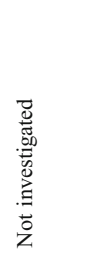 & 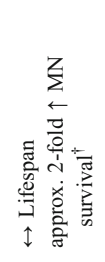 & 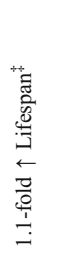 & 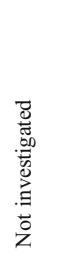 & 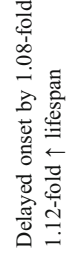 & 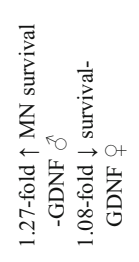 & 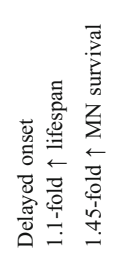 & $\begin{array}{l}\text { 总 } \\
\text { 岕 } \\
\stackrel{0}{z}\end{array}$ & 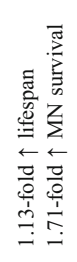 & 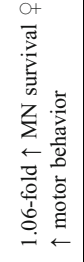 \\
\hline 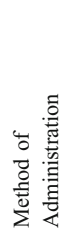 & 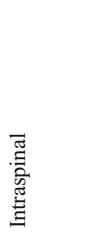 & $\vec{U}$ & 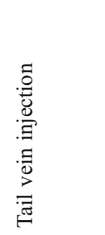 & 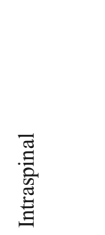 & 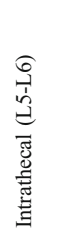 & 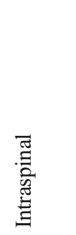 & 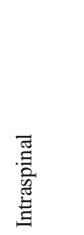 & 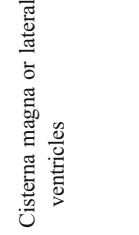 & 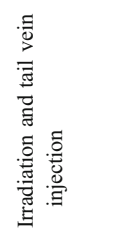 & 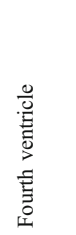 & 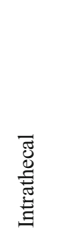 & 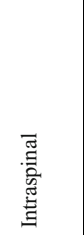 \\
\hline 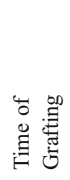 & 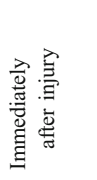 & 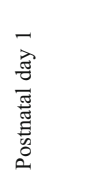 & 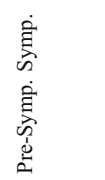 & 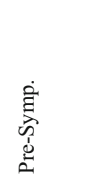 & 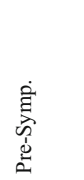 & 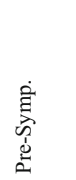 & 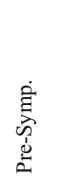 & 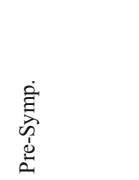 & 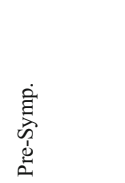 & 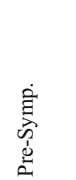 & 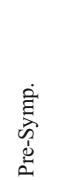 & 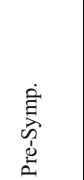 \\
\hline 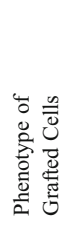 & 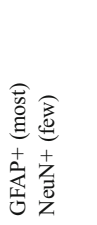 & 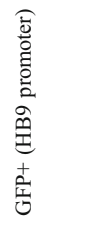 & 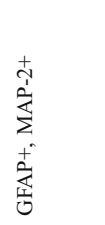 & 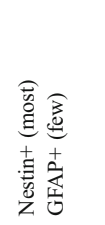 & 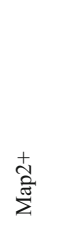 & 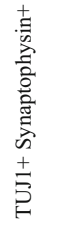 & 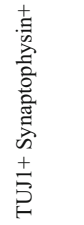 & 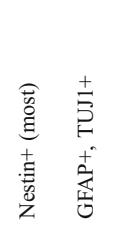 & $\overleftrightarrow{\mathrm{z}}$ & & 恚 & 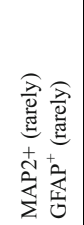 \\
\hline 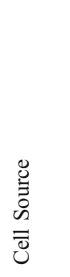 & 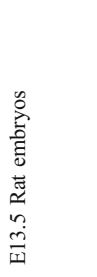 & 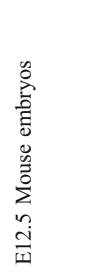 & 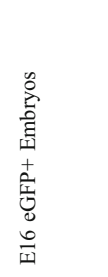 & 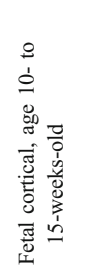 & 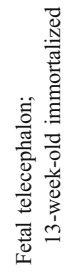 & 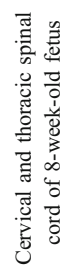 & 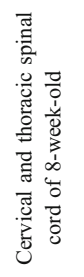 & 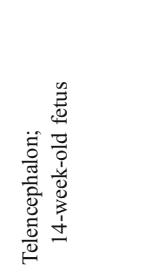 & 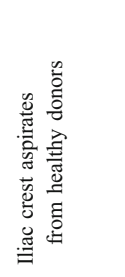 & 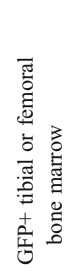 & 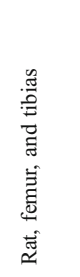 & 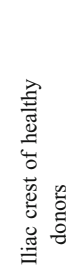 \\
\hline 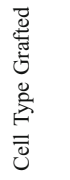 & 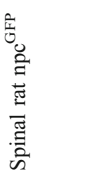 & 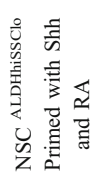 & $\begin{array}{l}\text { U. } \\
Z \\
\text { 怘 }\end{array}$ & 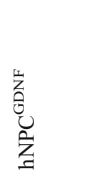 & $\begin{array}{l}\text { 剀 } \\
\text { 足 }\end{array}$ & 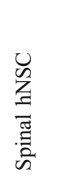 & 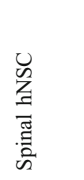 & 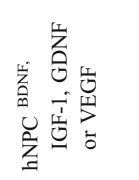 & $\sum_{\substack{0 \\
.}}$ & 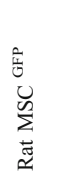 & 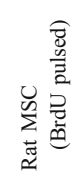 & 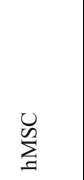 \\
\hline $\begin{array}{l}\frac{\overline{0}}{0} \\
\frac{0}{2}\end{array}$ & 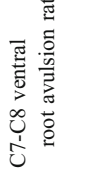 & 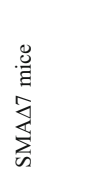 & 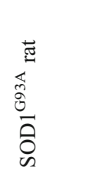 & 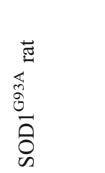 & 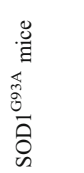 & 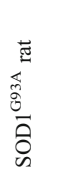 & 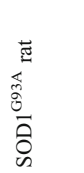 & 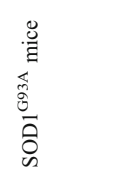 & 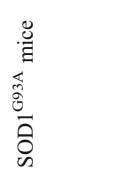 & 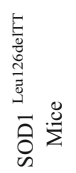 & 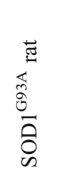 & 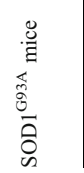 \\
\hline
\end{tabular}




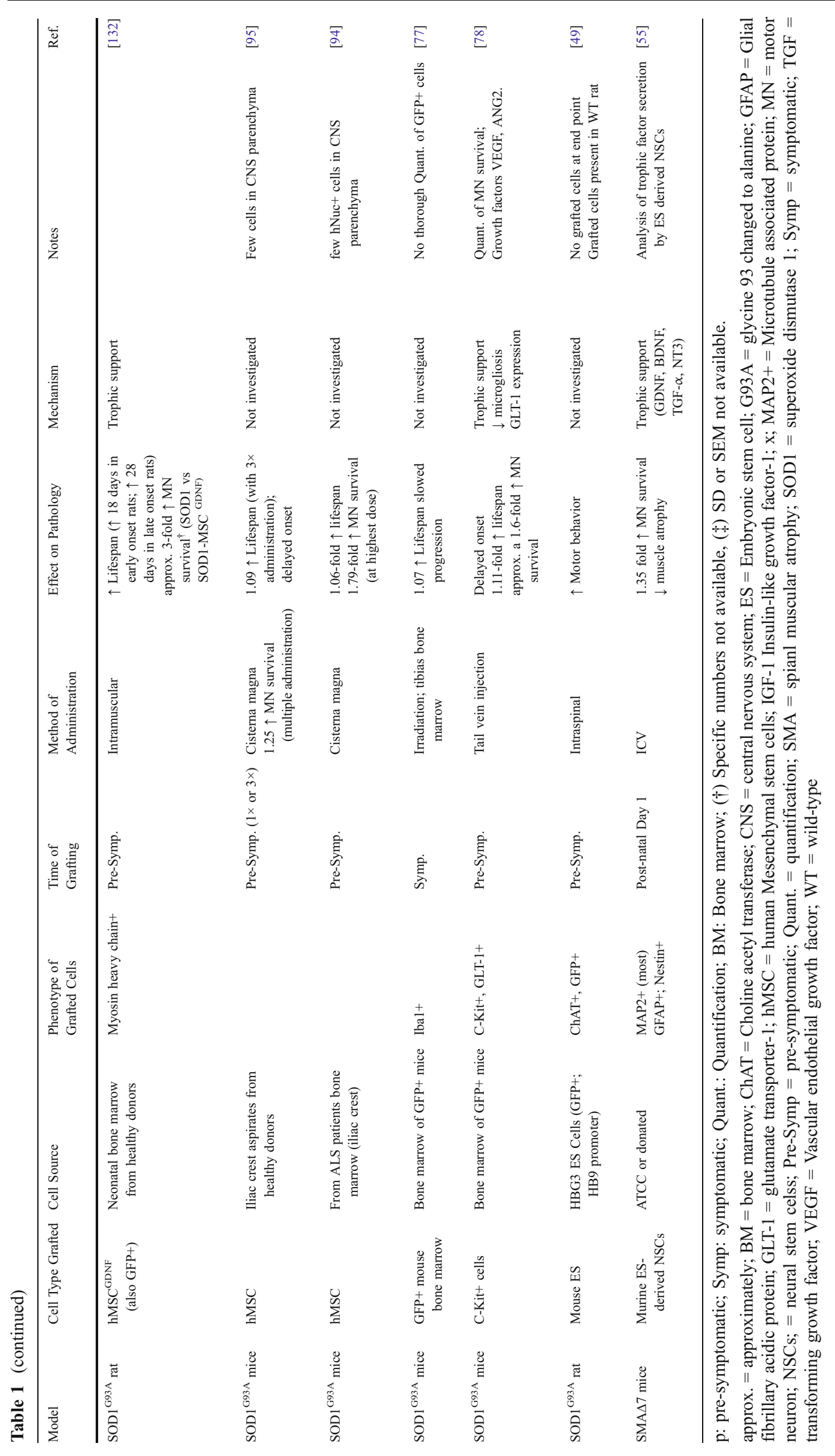


extension in the lifespan of a mouse model of SMA [62]. However, neither study demonstrated evidence indicating that the observed benefits were directly associated with the formation of functional motor units by the transplanted cells. Moreover, although not as efficient, the transplantation of undifferentiated ALDH: aldehyde dehydrogenase; SSC: side scatter; NSCs resulted in a significant increased survival of SMA mice. In a later publication, Corti et al. [63, 64] proceeded to grafting Lewis ${ }^{+}$; $\mathrm{CXCR} 4^{+}$mouse NSCs differentiated toward an $\mathrm{MN}$ cell fate directly into the spinal cords of SOD $1^{\mathrm{G} 93 \mathrm{~A}}$ transgenic mice model of ALS and $n m d$ mice. Again, transplants into $\mathrm{SOD} 1^{\mathrm{G} 93 \mathrm{~A}}$ transgenic mice extended the lifespan and reduced MN loss. The fate of transplanted cells at disease end-stage suggests that $17.6 \%$ of the grafted cells expressed both MN markers HB9 and choline acetyl transferase, and some of these extended axons in to the ventral roots [64]. In their later study, nmd mice were transplanted alone or in combination with the pharmacological paradigm previously developed by Deshpande et al. [46] and resulted in an extension of the lifespan. Interestingly, the beneficial effects were not only induced by the formation of neuromuscular junction from grafted MNs, but also via the modulation of the spinal microenvironment resulting in decreased neuroinflammation [63]. Similar studies by Gao et al. [65, 66] have also suggested that human NSC-derived MNs can ameliorate motor function following neonatal sciatic nerve injury in rats. At 3 months post-transplantation, $51 \%$ of the transplanted cells were cholinergic and 6.4\% of NMJ in the gastrocnemius muscle were contacted by grafted cells [66]. This is very significant data, as it used human cells that are suitable for transplantation in patients, actually generated from our own laboratory. However, in our hands it has not been possible to produce any motor neurons under very similar culture and transplant conditions used in these articles. Our most parsimonious explanation of this difference may be related to the way the cells were labelled prior to transplantation. Unfortunately, Gao et al. $[65,66]$ did not use human specific markers to label the new human motor neurons in their transplants. Thus, it remains possible that pre-labelling the cells with adenoassociated virus shortly before transplantation allowed a small amount of live virus to be transplanted with the cells, which then infected the host rat MNs.

Many of the beneficial effects observed in the aforementioned studies have been attributed to the generation of MN-like cells. However, successful MN replacement strategy would necessitate the formation of long tracts of axonal outgrowth and the formation of functional neuromuscular junctions by the grafted cells. Unfortunately, this was only investigated in a few of these studies, and only Deshpande et al. [46] and Yohn et al. [48] further demonstrated that the newly formed connections were functional in their models. Without this valuable information it remains possible that the functional improvements in locomotor function observed are due to the presence of other neuronal or non-neuronal cells in the transplant, such as progenitors, nonmotor neurons, astrocytes, and oligodendrocytes. These cells have been shown to secrete growth factors, and in some cases make connections with host motor neurons, thus potentially modulating their function and survival. However, in a sense, this is a side effect of the primary goal of these studies, which was to create motor neurons that project to the muscle. If other mechanisms of support were the end result, perhaps it would be better to tailor the cells to fit this role. Finally, in translating this work to human studies, it is clear that the large distances any motor neurons will have to traverse and the time it would take to reach the muscle may be a limiting factor in an aggressive diseases, such as ALS and SMA. Further studies showing efficacy in larger animals, such as the rat, pig, and monkey will be crucial to move this fascinating area of motor neuron replacement forward.

\section{Motor Neuron Protection Rather Than Replacement as a Therapeutic Approach for MN Disease}

Clearly, many studies support a role for intrinsic pathways of MN degeneration in ALS. In support of this idea, removal of the SOD1 mutation from MNs resulted in a significant delay in disease onset [67]. However, in this same article, the authors showed that while delaying onset, removal of mutant SOD1 from MNs had surprisingly little effect on disease duration. Earlier studies in 2003 by Clement et al. [50] generated substantial evidence that damage to MNs could be derived from noncell autonomous processes. Using chimeric mice composed of a combination of normal and mutant SOD1 expressing cells, the authors demonstrated that neuronal or non-neuronal that do not express mutant SOD1 can significantly delay degeneration and extend the survival of mutant SOD1 expressing motor neurons. Further studies from the same group then revealed that genetic deletion of mutant SOD1 from either microglia or astrocytes had little effect on disease onset, but dramatically increased survival of animals after disease onset suggesting a strong modifying ability of these cells on disease progression [67, 68]. As healthy motor neurons have been shown to be more susceptible to degeneration when exposed to a toxic microenvironment neuronal support rather than replacement strategies become particularly appealing approaches. To date, a substantial number of studies using an assortment of cell types and modes of administration have now investigated the effect non-neuronal cell transplantation strategies on 
MN degeneration. Interestingly, in sharp contrast to the neuronal replacement approach, the majority of these studies have been conducted in mutant SOD1 animal models of ALS.

\section{Using Non-Neural Cells to Support Dying Motor Neurons}

\section{Microglia and Hematopoietic-Derived Stem Cells}

Microglia are the resident immune cells of the CNS parenchyma, represent over $10 \%$ of the cell population in the healthy brain and spinal cord and are of myeloid origin $[69,70]$. In the unperturbed CNS, microglia are constantly surveying the microenvironment for damage which causes a rapid modification of the cell phenotype termed activation; a graded, diverse and highly dynamic response influenced by the nature of the insult and surrounding activation signals [71-73]. In an elegant study, transplantation of wild-type bone marrow in neonatal PU.1 knock-out mice with familial ALS extended lifespan and attenuated MN degeneration [74]. In this experimental paradigm, CNS microglia and the cells of the peripheral immune system of grafted mutant SOD1 animals were entirely donor derived. Whole body irradiation followed by bone-marrow transplantation is another approach that has been used to investigate the role of donor derived microglial cells in ALS. This method enables infiltration of mononuclear phagocytes into the CNS and can result in a 2- to 50-fold increase in donor derived microglial cells [75]. This strategy resulted in a significant amelioration in disease phenotype in mutant SOD1 ${ }^{\mathrm{G} 93 \mathrm{~A}}$ transgenic mice [76-78]. However, the beneficial effect observed in this study failed to be reproduced by others in $\mathrm{SOD} 1^{\mathrm{G} 93 \mathrm{~A}}$ or $\mathrm{SOD} 1^{\mathrm{G} 37 \mathrm{R}}$ mouse model of ALS [74, 79-81]. The differences observed in these studies could be due to variances in the percentage of chimerism obtained following the cell transplantation procedure, age of the animals at grafting and the degree of integration of donor derived-cells into the into the CNS parenchyma. Transplantation of human umbilical cord blood (hUCB) cells has also shown some beneficial effect in $\mathrm{SOD}^{\mathrm{G} 93 \mathrm{~A}}$ transgenic mice $[82,83]$. Based on these interesting animal studies, 6 sporadic ALS patients were transplanted, with granulocyte colonystimulating factor-primed peripheral blood progenitors from human leucocyte antigen matched donors following whole body irradiation and maintained on immunosuppressants to prevent graft-versus-host-disease (GHVD) [84]. Engraftment was confirmed in all patients and postmortem analysis of spinal tissues showed various degrees of donor cell contribution in zones of MN distress. However, no clinical benefit from this treatment was observed. The lack of effect seen in this study could be due, in part, to the insufficient integration of grafted cells into the CNS parenchyma, the timing of cell transplantation or the inability of these cells to provide neuroprotection. However, as stated by the authors, as these bone marrow derived cells have the capacity to home to zones of CNS distress, the genetic modification of these cells to increase their trophic potential could be of value for future ALS therapeutics.

\section{Mesenchymal Stem Cells}

Mesenchymal stem cells (MSCs) are multipotent nonhematopoietic stem cells that can be isolated from the bone marrow and expanded to large numbers in culture [85-87]. They are easy to isolate, can be autologously transplanted, are capable of homing to zones of cellular distress and have been shown to have many positive effects in a wide variety of disease models including those for neurological illnesses $[88,89]$. MSCs have the capacity to differentiate into cells of mesenchymal lineage (bone, cartilage, fat and myoblast) they have also be suggested to adopt "astrocytic like" and "neuronal like" cell fates [90-92]. In keeping with the different views on the possible phenotypic fate of MSCs, some studies have reported an extension in the lifespan and an increase in MN survival in mutant SOD1 mouse models of ALS following MSCs transplantation [93-96], whereas others have not [97]. Interestingly, in line with MSC transplantation therapy for other disorders, while cells appear to move into areas of damage they only survive for brief periods of time and, in most cases, cannot be found in the CNS parenchyma a few weeks after transplantation. Any protective effects observed may have been caused by the transient production of trophic factors by transplanted cells. Another possibility is that immunomodulation by grafted cells, resulting in a decrease in gliosis and general inflammation, could also contribute to neuroprotection [93]. Interestingly, the transplantation of MSCs directly into the sciatic nerve following a crush injury also prevented denervation of neuromuscular junctions and improved motor performance [98]. These beneficial effects were greater when MSCs were primed to adopt an astrocyte-like morphology which induced the cells to produce more protective growth factors such as brain-derived neurotrophic factor (BDNF); insulin-like growth factor (IGF)-1.

Of great interest to the field is the first in man phase I clinical trial where mesenchymal cells have been directly transplanted into the spinal cord of patients with ALS. While there were no dramatic improvements in the patient rating scores this study did show that large volumes of cell suspension (remarkably up to one $\mathrm{ml}$ in three injection sites) could be injected into the living human spinal cord with no adverse effects $[99,100]$. One could argue that the 
use of mesenchymal cells for direct transplantation into the spinal cord may be premature due to the lack of evidence that these cells can integrate and survive for long periods following direct spinal injection (all of the studies using mesenchymal stem cells described above have administered the cells through an intrathecal or intravenous approach). However, recently, a study by Mazzini and colleagues denoted that there is at least some survival of human mesenchymal cells following direct injection into the spinal cord in SOD1 ${ }^{\mathrm{G} 93 \mathrm{~A}}$ mice [101]. In this study, the authors suggested that transplanted hMSCs showed considerable migration capabilities and delayed $\mathrm{MN}$ degeneration via modulating gliosis. However, transplanted cells rarely expressed neural markers and likely did not functionally integrate into the CNS parenchyma. Furthermore, the authors used a dye to label the cells prior to transplantation which can potentially leak into surrounding tissues if the transplant does not survive. The gold standard in these studies is to use human specific antibodies to track the cells and prove they have survived. Regardless of these technical problems, the versatility and innate trophic as well as immunomodulatory potential of MSCs make them an interesting candidate for cell based therapies. Further characterization of the mechanisms associated with neuroprotection need to be studied, and perhaps their survival and integration in larger animal spinal cords should be investigated prior to moving forward in further human trials.

\section{Human NT2N and Sertoli Cells}

Human NT2N neurons were derived from a human teratocarcinoma cell line and display properties similar to that of primary neurons following a long differentiation protocol $[102,103]$. Following bilateral intraspinal transplantation into $\mathrm{SOD}^{\mathrm{G} 93 \mathrm{~A}}$ transgenic mice, hNT cells were shown to survive and lead to improvements in motor behavior (Willing et al. in 2001; Garbuzova-Davis et al. in 2001; Garbuzova-Davis et al. in 2002; and GarbuzovaDavis et al. in 2006). However, none of the studies revealed a significant effect of hNT cell transplantation on the lifespan of transgenic mice and the effect of grafted cells on motor neuron survival was not investigated. In another study, transplantation of Sertoli cells into the spinal cord of SOD $1^{\mathrm{G} 93 \mathrm{~A}}$ mice increased $\mathrm{MN}$ survival proximal, but not distal to the transplant site (Hemendinger et al. in 2005). Sertoli cells are normally found within the testes where they provide nutritional support and generate an immunoprivileged environment for the developing spermatogonia [104]. Although grafted Sertoli cells had no effect on the lifespan of the SOD $1^{\mathrm{G} 93 \mathrm{~A}}$ mouse and no surviving cells were found by histological analysis, the beneficial effect observed of
MN numbers may be attributed to the secretion of trophic factors, such as vascular endothelial growth factor (VEGF); insulin-like growth factor-1 (IGF-1); ciliary neurotrophy factor (CNTF) by the cells before they died. Although this is an interesting source of tissue, more work needs to be done to establish how reliably these cells can survive in grafted animals and their toxicity profiles before they can be used in clinical trials on humans with motor neuron diseases.

\section{Using Neural Cells as Support Dying Motor Neurons}

Neural tissues represent a more natural source for transplantation into animal models of motor neuron disease and ultimately patients. They may be expected to integrate into the host tissue and survive for long periods of time, incorporating into the damaged area, and providing long-term support for dying motor neurons.

\section{Astrocytes}

Astrocytes are the most abundant glial cell type in the brain and spinal cord, representing approximately $60 \%$ of total CNS cells [105]. These cells provide metabolic support to neurons, modulate and regulate synaptic strength via glutamate removal, regulate blood flow, maintain the $\mathrm{BBB}$, and contribute to the regulation of CNS immune reactivity [106]. Lepore et al [107], targeted multisegmental delivery of rodent glial restricted precursors (GRP) to the cervical spinal cord of a rat model of ALS. GRP cells are late glial precursors that have the ability to differentiate into oligodendrocytes and astrocytes [108]. Transplantation of these cells reduced $\mathrm{MN}$ degeneration, slowed the decline in locomotor and respiratory function, and extended survival and disease duration in mutant SOD $1^{\mathrm{G} 93 \mathrm{~A}}$ rats. The transplanted cells efficiently differentiated into astrocytes and neuroprotection was found to be mediated, in part, by the ability of the transplanted cells to maintain normal expression of the glutamate transporter glutamate transporter-1 (GLT-1) and reduce microgliosis. It is clear that the rodent GRP cells used in this study could not be used in humans. Thus, it would now be of great interest to see if human GRP cells can also have these very significant functional effects in preclinical disease models, and ultimately human patients with ALS.

\section{Human NSCs and Progenitor Cells}

Human NSCs and progenitor cells have been isolated from either the cortex or spinal cord of postmortem human fetal 
samples and used in transplant studies in mouse and rat models of ALS. Our laboratory has extensively studied cells derived from the fetal cortex grown in culture as 3dimensional aggregates termed "neurospheres" in response to the mitogens epidermal growth factor and fibroblast growth factor-2. We have shown that these cells are regionally specified [109-112] and have a limited lifespan of approximately 50 population doublings [113, 114], and at later passages preferentially differentiate into astrocytes and some neurons, but not oligodendrocytes [109, 114, 115]. As such, we have termed these bi-potent neural progenitor cells (hNPC) rather than multi-potent selfrenewing NSCs. These cells can be efficiently banked. The most important aspect of these cells is that while they do not make motor neurons in the culture dish or after transplantation, they do not make teratomas, which is in direct contrast to more powerful human embryonic stem (hES) or induced pluripotent stem (iPS) cells. Clearly, major efforts have been made to differentiate hES and hiPS cells away from pluripotency to reduce the risk of teratoma formation. Moreover, differentiation of hES or iPS cells toward neural tissues is constantly being optimized in this rapidly moving field. However, at this stage if motor neurons are not the aim, it may be more suitable to use hNPCs rather than hES or hiPS cells in clinical trials.

In other studies, similar cells have been isolated from the cervical-thoracic spinal cord of a single 8-week-old human fetus, and have been expanded in culture in monolayers using fibroblast growth factor-2 as the mitogen. These cells have been described as NSCs by others [116] and a clinical grade bank termed (NSI-566RSC) has been derived. Neural Stem Inc. (at Rockville, MD 20850), in collaboration with the Koliatsos Laboratory, have proceeded to transplant NSI566RSC cells in mouse and rat SOD $1^{\text {G93A }}$ models of ALS [117-120]. In the study by Yan et al. [121], low passage NSI-566RSC appears to readily differentiate into neuronal cells following grafting. In the sham, avulsion, or excitotoxic lesion model, these cells predominantly matured and differentiated into neuronal cells (70\% TUJ1+ cells) expressing glutamatergic and gamma-aminobutyric acid (GABA)ergic neurotransmitter markers [121]. The remaining graft-derived cells were found to express nestin or the astrocyte marker glial fibrillary acidic protein (GFAP). Moreover, in a series of experiments, transplantation of these spinal human neural stem cells (hNSCs) into the parenchyma of SOD $1^{\mathrm{G} 93 \mathrm{~A}}$ rats or mice resulted in a modest extension in their lifespan [118, 119]. The phenotypic fate of TUJ1+ neuronal cells was not extensively investigated following grafting into SOD1 animals, but graft-derived TUJ1+ neurons were found to express synaptophysin and integrate into the motor neuron circuitry [117]. Although some of the beneficial effects of transplanted cells observed in the previously mentioned studies may come from graft-derived gamma-aminobutyric acid (GABA)ergic inhibition of motor neurons, this has not been directly investigated in SOD1 animals models [117120]. However, Xu et al. [119] showed a significant increase in the expression of brain derived neurotrophic factor (BDNF); glial cell line-derived neurotrophic factor (GDNF); vascular endothelial growth factor (VEGF) in the spinal cords of grafted animals, suggesting that motor neuron survival may be attributed to increased trophic support. It could be suggested that transplantation of new neurons in the cord may interfere with the existing neuronal network through the generation of deleterious connections. Moreover, the long-term survival of neuronal cells in a chronic degenerative microenvironment is likely to be difficult to accomplish. However, many of these issues are difficult to address in animal models due to the short duration of disease progression. Therefore, carefully designed patient studies are an appropriate way forward to begin addressing these issues. Accordingly, a Food and Drug Administration-approved phase 1 clinical trial testing the feasibility and safety of direct transplantation of NSI-566RSC produced by neural stem cells (NSCs) into the spinal cord of ALS patients is currently ongoing (http://clinicaltrials.gov, identifier \#NCT01348451) [122].

\section{Using Stem Cells as a Vehicle for the Delivery of Therapeutic Compounds}

Interestingly, nearly all of the transplantation strategies previously mentioned have attributed any increase in $\mathrm{MN}$ survival or improved motor behaviour and extension in lifespan to the production of trophic factors or other neuroprotective or immunomodulating molecules by the grafted cells. In other work, a direct beneficial effect of growth factors, such as GDNF, IGF-1, CNTF, and VEGF on motor neuron survival and function has been shown in experimental models of ALS [123]. However, the observed beneficial effect of these molecules in ALS animal models failed to be translated to humans, in which delivery of these growth factors did not ameliorate disease progression, and in some cases caused serious side effects [124-126]. Among the many issues with these clinical studies, the major problem was likely to be appropriate delivery of the growth factor directly to the degenerating motor neurons in the brain and spinal cord. These proteins do not readily penetrate the spinal cord from either peripheral administration or direct administration to the cerebrospinal fluid. Direct delivery of growth factors using gene therapy approaches is an exciting area of study [123], and there is 1 clinical trial currently ongoing in Sweden delivering VEGF protein directly to the cerebrospinal fluid of ALS patients (http://clinicaltrials.gov, identifier \#NCT01384162) 
and NCT00800501). Further clinical trials with viral vectors making growth factors need to be moved forward. However, cells within the CNS of patients are undergoing degeneration and further study is required to determine if the use these distressed cells to express growth factors to promote neuroprotection would be an efficient approach. An interesting alternative is ex vivo gene therapy in which the cells are genetically modified prior to transplantation to secrete powerful growth factors, or other molecules of interest. This approach provides the degenerating brain and spinal cord with cells having intrinsic neuroprotective potential but also altered to be more effective. This would also circumvent issues associated with classical protein delivery approaches, such as the inability to cross the blood-brain barrier, adverse side effects caused by systemic delivery, and short protein half-life. Supporting this approach, transplantation of hNPCs derived from the human fetal cortex expressing GDNF had a significant effect on MN survival compared to wild-type hNPCs in the SOD $1^{\mathrm{G} 93 \mathrm{~A}}$ rat model of ALS [23]. However, no effect on paralysis in the targeted muscles was observed in these studies. In another study by Park et al. [127], hNSCs derived from the fetal telencephalon-expressing GNDF or IGF-1 were transplanted into the cisterna magna or lateral ventricles and enhanced $\mathrm{MN}$ survival. However, in this study, Park et al. [127] observed a significant decrease in the survival and irritable behaviors of their SOD $1^{\mathrm{G} 93 \mathrm{~A}}$ transgenic mice following transplantation of GDNFexpressing cells. Interestingly, intracerebroventricular administration of GNDF in patients with Parkinson's disease has also been associated with side effects including nausea, loss of appetite, tingling, depression, and more [128, 129]. The side effects associated with widespread CNS delivery of GDNFexpressing cells argue for the use of a site-specific targeting technique for transplantation therapy. Interestingly, in 1 other study, an immortalized hNSC line derived from fetal telencephalon and modified to produce VEGF was intrathecally injected into $\mathrm{SOD} 1^{\mathrm{G} 93 \mathrm{~A}}$ transgenic mice [130]. Although a thorough quantification of grafted cell fate was not performed, some hNSCs were shown to adopt a neuronal (MAP2+) or astrocytic (GFAP+) phenotype, and this led to increased survival and a reduction in symptoms of transgenic animals. Interestingly, $63.9 \%$ of total transplanted cells were shown to survive, and among these only $12.3 \%$ were found in the CNS parenchyma 4 weeks after grafting. The remaining cells were found along the meninges of the spinal cord.

An alternative approach to protecting motor neurons in the spinal cord is to target the degenerating connections within the muscle. Mohajeri et al. [131] grafted genetically modified GDN- secreting myoblasts into the muscle tissue of the $\mathrm{SOD} 1^{\mathrm{G} 93 \mathrm{~A}}$ transgenic mouse and showed extended maintenance of neuromuscular junctions improvement of the disease phenotype. In fact, GDNF-secreting cells delayed the deterioration of motor behavior, slowed muscle atrophy, and enhanced motor neuron survival. More recently, we have followed-up on this approach by transplanting hMSC genetically modified to express GDNF into various muscle groups of the $\mathrm{SOD} 1^{\mathrm{G} 93 \mathrm{~A}}$ transgenic rat. In contrast to our intraspinal injections of hNPC-secreting growth factors, transplantation of GDNF secreting cells into the muscle resulted in an increase in $\mathrm{MN}$ numbers and enhanced survival [132]. Combining stem cell transplantation and ex vivo gene therapy is a compelling approach, as it harnesses the innate neuroprotective capabilities of stem cells and provides a site specific delivery mechanism for potent therapeutic compounds. Recently, BrainStorm Cell Therapeutics Ltd. (12 Bazel St., POB 10019 Kiryat Aryeh, Petach Tikva, Israel 49001) has been approved to conduct a phase I/II clinical trial of NurOwn, an autologous stem cell therapy using mesenchymal bone marrow stromal cells secreting neurotrophic factors for patients with ALS (http:// clinicaltrials.gov, identifier \#NCT01051882). Although most studies have investigated the potential of growth factor secreting cells, other candidates include molecules capable of regulating the immune response, glial activation, or excitotoxic stress, such as interleukin-4, transforming growth factor beta (TGF- $\beta$ ), or the glutamate transporter GLT-1.

\section{Are iPS Cells the Future of Cell-Based Therapy for MN Disorders?}

As previously discussed, a variety of cell types have been assessed in animal models of MN disorders for their efficiency in alleviating disease-related symptoms and pathology by replacing lost MNs, protecting remaining neuronal cells, or by modulating the CNS microenvironment. However, despite their great therapeutic potential, the use of embryonic stem (ES) or fetal-derived cells is hurdled by a number of concerns, including availability, the possibility of immune rejection and ethics. In 2006, Takahashi et al. [133] described how mouse embryonic or adult fibroblast could be reprogrammed to pluripotency by the expression of oct3/4, Sox2, c-Myc, and Klf4, under ES cell culture conditions and coined these iPS cells. Soon after, reprogramming of human somatic cells to a pluripotent state was achieved using similar approaches [134-136]. Similar to ES cells, iPS cells have the capacity to be differentiated into cells of endodermal, mesodermal, or ectodermal origin, and further lineage restriction can provide specific neural subtypes or astrocytes for CNS transplantation and disease modelling [137]. Moreover, iPS cells can be generated from a variety of adult somatic tissues, making the work material readily available and circumventing ethical issues associated with the use of cells 
from embryonic or fetal origin. Interestingly, reprogramming cells to a pluripotent state has been shown to cause the reversal of signs associated with aging in normal cells [138]. The possibility of autologous transplantation with iPS-derived cells resolves issues associated with graft rejection and complications resulting from long-term use of immunosuppressive drugs. However, the use of iPSderived cells for transplantation is not without its own problems or limitations. First, the generation, characterization, and differentiation of iPS cells is a time-consuming and costly procedure. In rapidly progressing diseases, such as ALS, autologous transplantation may not be currently feasible. Second, in cases of disorders associated with a genetic defect, transplantation of iPS-derived cells with disease-associated mutation may not be prudent. For example, cells expressing SOD1 mutations can cause the degeneration of healthy wild-type MNs in vitro and neuronal specific expression of mutant SOD1 is sufficient to induce motor neuron degeneration in an animal model [51, 52, 139]. Nevertheless, both in animal models and in human patients, it remains unclear as to when disease process is initiated and cells become dysfunctional or active participants in degeneration. Interestingly, following the differentiation into disease susceptible cell type, an overt phenotype is not always observed, even from cells carrying disease-associated mutations [137, 140]. This may indicate that aging or cellular stress challenges may be required to uncover or initiate a degenerative process. However, the absence of diseaseassociated phenotypes in some iPS-derived cells enhances their appeal for transplantation therapy.

Although autologous transplantation would be ideal in terms of circumventing immune rejection (even though this is not clearly based on recent rodent studies [141]), it would be enormously expensive to generate patient specific lines, characterize them in preclinical animal models, and then use them for treatment. There would have to be a shift in thinking along the lines of other cell therapies (cord blood or bone marrow transplants) in which iPS cell production methods were approved for clinical use in humans. However, another promising strategy is the banking of iPS cells expressing different variants of human leucocyte antigen [142]. This approach would significantly accelerate the transplantation process, as it would bypass the reprogramming of patient-specific fibroblasts, as well as the testing of new iPS cell lines for safety prior to transplantation. Moreover, it would significantly reduce the cost associated with the generation of patient-specific cells. Another important consideration prior to moving forward with iPS-derived cells for transplantation is safety. As for human embryonic stem cells, producing a final cell population devoid of undifferentiated iPS cells and lacking the capacity to form teratomas (while retaining the ability to produce surviving functional transplants) will have to be demonstrated. However, transplantation of iPS-derived cells into animal models of sickle cell anemia, hemophilia, Parkinson's disease, spinal cord injury, and diabetes has shown therapeutic potential [143-147]. More recently, transplantation of Pax7-induced iPS-derived myogenic progenitors into dystrophic mice results in extensive engraftment and an improvement in the contractile properties of treated muscles [148]. Thus, these types of approaches hold out much hope for future trial. Although, to our knowledge, iPS-derived cells have not been proposed for use in clinical trial, GERON corporation (Menlo Park, CA 94025 USA) has recently initiated a phase 1 clinical trial for the use of human embryonic stem cells (hESC)derived oligodendrocyte progenitor cells (GRNOPC1) in patients with spinal cord injury (http://clinicaltrials.gov, identifier \#NCT01217008). This trial represents another step forward bringing cell-based therapies for traumatic or neurodegenerative disease closer to the clinic.

\section{Rationale for Cell Transplantation Therapy}

The severity of the disease, coupled with the lack of effective treatment, has made ALS and SMA prime targets for cell transplantation. As previously described, transplantation approaches have great potential as a therapy for $\mathrm{MN}$ disorders and other neurodegenerative conditions. However, the enthusiasm associated with this new approach must be matched by an equally strong rationale prior to proceeding to clinical trials $[149,150]$. Ideally, this should include demonstrating that the efficacy and safety of the treatment is reproduced across multiple studies. Importantly, for proper translation of preclinical work to human disorders, experimental study design in the animal models of motor neuron disease should carefully consider timing of the treatment. For example, the majority, if not all, transplantation studies carried out in ALS animal models have been performed in pre-symptomatic animals. Although this approach may apply to motor neuron pools not yet affected by the disease (when a patient is diagnosed with definite ALS), it may be of no therapeutic value for areas in which degeneration has already begun. Thus, to better determine the window of effectiveness of potential therapies, investigators should assess therapeutic approaches at multiple time points in animal models prior to moving forward to clinical translation. For ALS, many studies support the feasibility of an approach focused on neuronal protection. Indeed, motor neuron protection provided by the direct transplantation of cells into the spinal cord of mutant SOD1 animals has provided convincing evidence and promoted clinical translation of this approach. Moreover, preclinical studies have demonstrated the feasibility of direct parenchymal transplantation of stem cells and transplantation techniques are being continuously optimized 
[151-153]. Accordingly, a clinical trial, the first of its kind, using direct transplantation of human spinal cord progenitors in ALS patients is presently underway and has recently been reviewed [122]. In contrast, further evidence demonstrating the efficiency or feasibility of cell transplantation for neuronal replacement/support therapy in SMA is still needed. In fact, only 2 studies investigating stem cell transplantation in an animal model of SMA has been published to date and are previously described $[55,62]$. These studies investigated neuronal replacement as a therapeutic strategy for SMA, experimental paradigms using the currently available SMA models have yet to explore the possible therapeutic potential of transplanting stem cells for neuronal support. Moreover, transplantation therapy for types 1 and 2 SMA patients requires optimization of methods for efficient and perhaps minimally invasive delivery of stem cells into the spinal cords of infants. Hence, prior to pursuing cell transplantation strategies for SMA into the clinic, further investigation is clearly warranted.

\section{Conclusion and Future Perspectives}

Significant progress investigating cell transplantation therapy for motor neuron disease, in particular, ALS, has occurred in recent years. Optimization of the transplantation techniques, combined with grafting of appropriate cell type expressing, the most potent neuroprotective molecules will undoubtedly lead to the generation of successful therapeutic strategies for ALS and perhaps other motor neuron disorders. In addition, future studies should also investigate cell transplantation strategies aimed at preventing the degeneration of cortical motor neuron, as significant degeneration of this cell population also contributes to ALS pathology and is recapitulated in mutant SOD1 transgenic mice [55, 154, 155]. Moreover, as mutations in SOD1 are only responsible for $2 \%$ of all ALS cases, studies corroborating the therapeutic effect of stem cell therapy in newly available models of ALS should be performed. Finally, as effective therapeutic strategies for $\mathrm{MN}$ disease will undoubtedly require grouping multiple

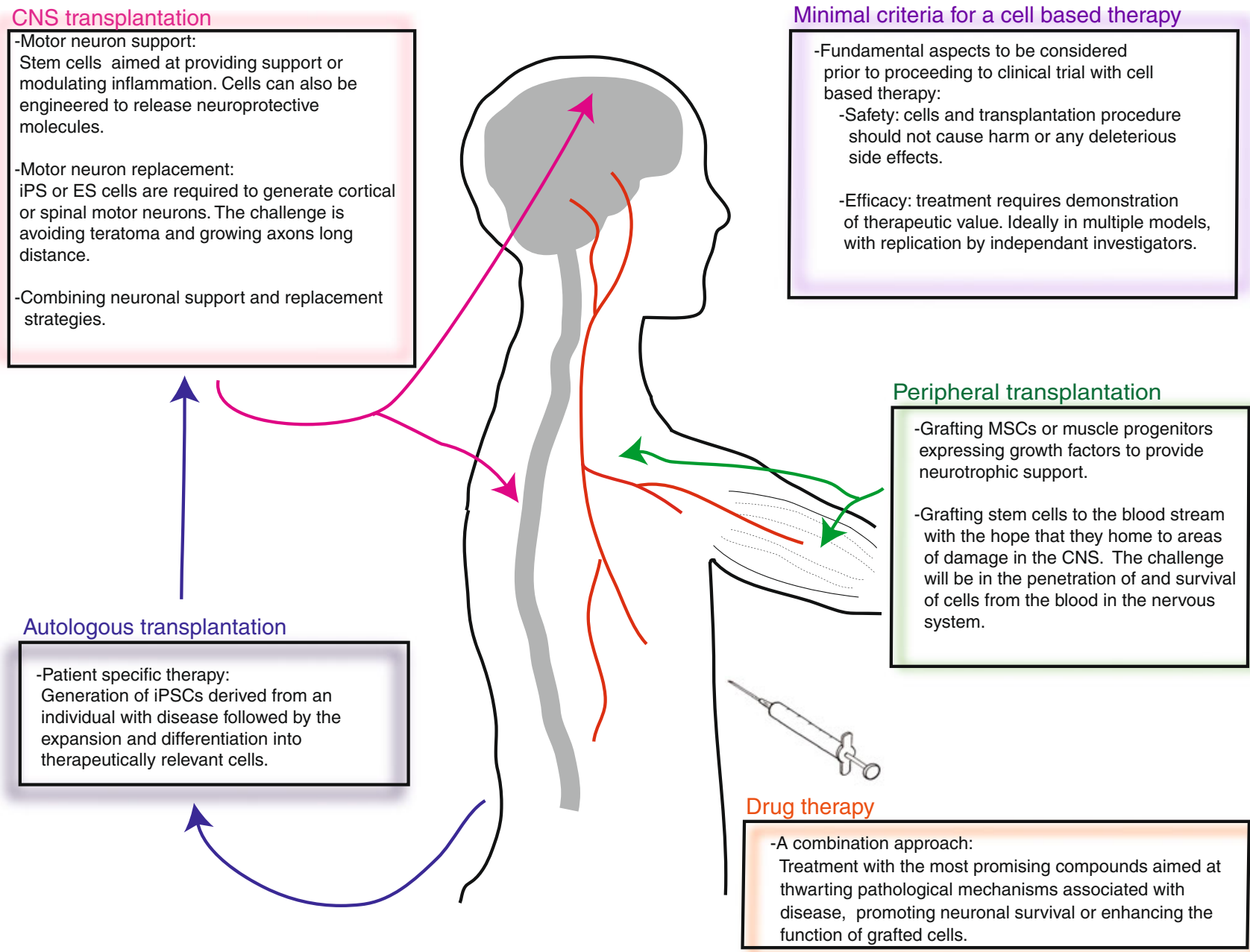

Fig. 1 Schematic representation of possible therapeutic approaches for amyotrophic lateral sclerosis and other motor neuron disorders. CNS $=$ central nervous system; ES embryonic stem cells; iPS = induced pluripotent stem cells; MSCs = mesenchymal stem cells 
therapeutic approaches (Fig. 1), experimental studies should now be designed to explore combination therapies.

Acknowledgments The authors would like to thank Brandon Shelley, Dhruv Sareen, and Virginia Mattis for their helpful discussion, as well as Jacalyn McHugh for editing the manuscript. Full conflict of interest disclosure is available in the electronic supplementary material for this article.

Open Access This article is distributed under the terms of the Creative Commons Attribution Noncommercial License which permits any noncommercial use, distribution, and reproduction in any medium, provided the original author(s) and source are credited.

\section{References}

1. Kanning KC, Kaplan A, Henderson CE. Motor neuron diversity in development and disease. Annual review of neuroscience 2010;33:409-440.

2. Rothstein JD. Current hypotheses for the underlying biology of amyotrophic lateral sclerosis. Ann Neurol 2009;65(suppl 1:S3-S9).

3. Saito M, Tomonaga M, Narabayashi H. Histochemical study of the muscle spindles in parkinsonism, motor neuron disease and myasthenia. An examination of the pathological fusimotor endings by the acetylcholinesterase technic. J Neurol 1978;219:261-271.

4. Swash M, Fox KP. The pathology of the human muscle spindle: effect of denervation. J Neurol Sci 1974;22:1-24.

5. Swash M, Leader M, Brown A, Swettenham KW. Focal loss of anterior horn cells in the cervical cord in motor neuron disease. Brain 1986;109(pt 5):939-952.

6. Beleza-Meireles A, Al-Chalabi A. Genetic studies of amyotrophic lateral sclerosis: controversies and perspectives. Amyotroph Lateral Scler 2009;10:1-14.

7. Zinman L, Cudkowicz M. Emerging targets and treatments in amyotrophic lateral sclerosis. Lancet Neurol 2011;10:481-490.

8. Millecamps S, Salachas F, Cazeneuve C, et al. SOD1, ANG, VAPB, TARDBP, and FUS mutations in familial amyotrophic lateral sclerosis: genotype-phenotype correlations. J Med Genet 2010;47:554-560.

9. Mackenzie IR, Rademakers R, Neumann M. TDP-43 and FUS in amyotrophic lateral sclerosis and frontotemporal dementia. Lancet Neurol 2010;9:995-1007.

10. Kaminski HJ, Richmonds CR, Kusner LL, Mitsumoto H. Differential susceptibility of the ocular motor system to disease. Ann N Y Acad Sci 2002;956:42-54.

11. Mannen T. Neuropathological findings of Onuf's nucleus and its significance. Neuropathology 2000;20(suppl):S30-S33.

12. Schroder HD, Reske-Nielsen E. Preservation of the nucleus Xpelvic floor motosystem in amyotrophic lateral sclerosis. Clin Neuropathol 1984;3:210-216.

13. Ravits JM, La Spada AR. ALS motor phenotype heterogeneity, focality, and spread: deconstructing motor neuron degeneration. Neurology 2009;73:805-811.

14. Gurney ME, Pu H, Chiu AY, et al. Motor neuron degeneration in mice that express a human $\mathrm{Cu}, \mathrm{Zn}$ superoxide dismutase mutation. Science 1994;264:1772-1775.

15. Howland DS, Liu J, She Y, et al. Focal loss of the glutamate transporter EAAT2 in a transgenic rat model of SOD1 mutantmediated amyotrophic lateral sclerosis (ALS). Proc Natl Acad Sci U S A 2002;99:1604-1609.

16. Turner BJ, Talbot K. Transgenics, toxicity and therapeutics in rodent models of mutant SOD1-mediated familial ALS. Prog Neurobiol 2008;85:94-134.
17. Frey D, Schneider C, Xu L, Borg J, Spooren W, Caroni P. Early and selective loss of neuromuscular synapse subtypes with low sprouting competence in motoneuron diseases. J Neurosci 2000;20:2534-2542.

18. Hegedus J, Putman CT, Gordon T. Time course of preferential motor unit loss in the SOD1 G93A mouse model of amyotrophic lateral sclerosis. Neurobiol Dis 2007;28:154-164.

19. Hegedus J, Putman CT, Gordon T. Progressive motor unit loss in the G93A mouse model of amyotrophic lateral sclerosis is unaffected by gender. Muscle Nerve 2009;39:318-327.

20. Hegedus J, Putman CT, Tyreman N, Gordon T. Preferential motor unit loss in the SOD1 G93A transgenic mouse model of amyotrophic lateral sclerosis. J Physiol 2008;586:3337-3351.

21. Fischer LR, Culver DG, Tennant P, et al. Amyotrophic lateral sclerosis is a distal axonopathy: evidence in mice and man. Exp Neurol 2004;185:232-240.

22. Fischer LR, Glass JD. Axonal degeneration in motor neuron disease. Neurodegen Dis 2007;4:431-442.

23. Suzuki M, McHugh J, Tork C, et al. GDNF secreting human neural progenitor cells protect dying motor neurons, but not their projection to muscle, in a rat model of familial ALS. PloS One 2007;2:e689.

24. Swarup V, Julien JP. ALS pathogenesis: recent insights from genetics and mouse models. Prog Neuropsychopharmacol Biol Psychiatry 2011;35:363-369.

25. Ilieva H, Polymenidou M, Cleveland DW. Non-cell autonomous toxicity in neurodegenerative disorders: ALS and beyond. J Cell biol 2009;187:761-772.

26. Shaw PJ, Eggett CJ. Molecular factors underlying selective vulnerability of motor neurons to neurodegeneration in amyotrophic lateral sclerosis. J Neurol 2000;247(suppl 1):I17-27.

27. Boillee S, Vande Velde C, Cleveland DW. ALS: a disease of motor neurons and their nonneuronal neighbors. Neuron 2006;52:39-59.

28. Lorson CL, Rindt H, Shababi M. Spinal muscular atrophy: mechanisms and therapeutic strategies. Hum Mol Gen 2010;19: R111-R118.

29. Lunn MR, Wang CH. Spinal muscular atrophy. Lancet 2008;371:2120-2133.

30. Coovert DD, Le TT, McAndrew PE, et al. The survival motor neuron protein in spinal muscular atrophy. Human molecular genetics 1997;6:1205-1214.

31. Crawford TO, Pardo CA. The neurobiology of childhood spinal muscular atrophy. Neurobiol Dis 1996;3:97-110.

32. Lorson CL, Hahnen E, Androphy EJ, Wirth B. A single nucleotide in the SMN gene regulates splicing and is responsible for spinal muscular atrophy. Proc Natl Acad Sci U S A 1999;96:6307-6311.

33. Feldkotter M, Schwarzer V, Wirth R, Wienker TF, Wirth B. Quantitative analyses of SMN1 and SMN2 based on real-time lightCycler PCR: fast and highly reliable carrier testing and prediction of severity of spinal muscular atrophy. Am J Hum Gen 2002;70:358-368.

34. Lefebvre S, Burlet P, Liu Q, et al. Correlation between severity and SMN protein level in spinal muscular atrophy. Nat Genet 1997;16:265-269.

35. Monani UR, Sendtner M, Coovert DD, et al. The human centromeric survival motor neuron gene (SMN2) rescues embryonic lethality in $\mathrm{Smn}(-/-)$ mice and results in a mouse with spinal muscular atrophy. Hum Mol Genet 2000;9:333-339.

36. Park GH, Kariya S, Monani UR. Spinal muscular atrophy: new and emerging insights from model mice. Current Neurol Neurosci Rep 2010;10:108-117.

37. Murray LM, Talbot K, Gillingwater TH. Review: neuromuscular synaptic vulnerability in motor neurone disease: amyotrophic lateral sclerosis and spinal muscular atrophy. Neuropathol Appl Neurobiol 2010;36:133-156. 
38. Silani V, Braga M, Ciammola A, Cardin V, Scarlato G. Motor neurones in culture as a model to study ALS. J Neurol 2000;247 (suppl 1):I28-36.

39. Wiese S, Herrmann T, Drepper C, et al. Isolation and enrichment of embryonic mouse motoneurons from the lumbar spinal cord of individual mouse embryos. Nat Protocol 2010;5:31-38.

40. Evans MJ, Kaufman MH. Establishment in culture of pluripotential cells from mouse embryos. Nature 1981;292:154-156.

41. Thomson JA, Itskovitz-Eldor J, Shapiro SS, et al. Embryonic stem cell lines derived from human blastocysts. Science 1998;282:1145-1147.

42. Miles GB, Yohn DC, Wichterle H, Jessell TM, Rafuse VF, Brownstone RM. Functional properties of motoneurons derived from mouse embryonic stem cells. J Neurosci 2004;24:78487858 .

43. Wichterle H, Lieberam I, Porter JA, Jessell TM. Directed differentiation of embryonic stem cells into motor neurons. Cell 2002;110:385-397.

44. Wichterle H, Peljto M. Differentiation of mouse embryonic stem cells to spinal motor neurons. Curr Protoc Stem Cell Biol 2008;5:1H.1.1-1H.1.9.

45. Wichterle H, Peljto M, Nedelec S. Xenotransplantation of embryonic stem cell-derived motor neurons into the developing chick spinal cord. Methods Mol Biol 2009;482:171-183.

46. Deshpande DM, Kim YS, Martinez T, et al. Recovery from paralysis in adult rats using embryonic stem cells. Ann Neurol 2006;60:32-44.

47. Harper JM, Krishnan C, Darman JS, et al. Axonal growth of embryonic stem cell-derived motoneurons in vitro and in motoneuron-injured adult rats. Proc Natl Acad Sci U S A 2004;101:7123-7128

48. Yohn DC, Miles GB, Rafuse VF, Brownstone RM. Transplanted mouse embryonic stem-cell-derived motoneurons form functional motor units and reduce muscle atrophy. J Neurosci 2008;28:12409-12418.

49. Lopez-Gonzalez R, Kunckles P, Velasco I. Transient recovery in a rat model of familial amyotrophic lateral sclerosis after transplantation of motor neurons derived from mouse embryonic stem cells. Cell Transplant 2009;18:1171-1181.

50. Clement AM, Nguyen MD, Roberts EA, et al. Wild-type nonneuronal cells extend survival of SOD1 mutant motor neurons in ALS mice. Science 2003;302:113-117.

51. Di Giorgio FP, Carrasco MA, Siao MC, Maniatis T, Eggan K. Non-cell autonomous effect of glia on motor neurons in an embryonic stem cell-based ALS model. Nat Neurosci 2007;10:608-614.

52. Nagai M, Re DB, Nagata T, et al. Astrocytes expressing ALSlinked mutated SOD1 release factors selectively toxic to motor neurons. Nat Neurosci 2007;10:615-622.

53. Weydt P, Yuen EC, Ransom BR, Moller T. Increased cytotoxic potential of microglia from ALS-transgenic mice. Glia 2004;48:179-182.

54. Zhao W, Beers DR, Henkel JS, et al. Extracellular mutant SOD1 induces microglial-mediated motoneuron injury. Glia 2010;58:231-243.

55. Corti S, Nizzardo M, Nardini M, et al. Embryonic stem cellderived neural stem cells improve spinal muscular atrophy phenotype in mice. Brain 2010;133:465-481.

56. Guo X, Johe K, Molnar P, Davis H, Hickman J. Characterization of a human fetal spinal cord stem cell line, NSI-566RSC, and its induction to functional motoneurons. J Tissue Eng Regen Med 2010;4:181-193.

57. Gritti A, Parati EA, Cova L, et al. Multipotential stem cells from the adult mouse brain proliferate and self-renew in response to basic fibroblast growth factor. J Neurosci 1996;16:1091-1100.
58. Kalyani A, Hobson K, Rao MS. Neuroepithelial stem cells from the embryonic spinal cord: isolation, characterization, and clonal analysis. Dev Biol 1997;186:202-223.

59. Reynolds BA, Weiss S. Clonal and population analyses demonstrate that an EGF-responsive mammalian embryonic CNS precursor is a stem cell. Dev Biol 1996;175:1-13.

60. Temple S. Division and differentiation of isolated CNS blast cells in microculture. Nature 1989;340:471-473.

61. Corti S, Locatelli F, Papadimitriou D, et al. Transplanted ALDHhiSSClo neural stem cells generate motor neurons and delay disease progression of nmd mice, an animal model of SMARD1. Hum Mol Genet 2006;15:167-187.

62. Corti S, Nizzardo M, Nardini $M$, et al. Neural stem cell transplantation can ameliorate the phenotype of a mouse model of spinal muscular atrophy. J Clin Invest 2008;118:3316-3330.

63. Corti S, Nizzardo M, Nardini M, et al. Motoneuron transplantation rescues the phenotype of SMARD1 (spinal muscular atrophy with respiratory distress type 1). J Neurosci 2009;29:11761-11771.

64. Corti S, Locatelli F, Papadimitriou D, et al. Neural stem cells LewisX+CXCR4+ modify disease progression in an amyotrophic lateral sclerosis model. Brain 2007;130:1289-1305.

65. Gao J, Coggeshall RE, Chung JM, Wang J, Wu P. Functional motoneurons develop from human neural stem cell transplants in adult rats. Neuroreport 2007;18:565-569.

66. Gao J, Coggeshall RE, Tarasenko YI, Wu P. Human neural stem cell-derived cholinergic neurons innervate muscle in motoneuron deficient adult rats. Neuroscience 2005;131:257-262.

67. Boillee S, Yamanaka K, Lobsiger CS, et al. Onset and progression in inherited ALS determined by motor neurons and microglia. Science 2006;312:1389-1392.

68. Yamanaka K, Chun SJ, Boillee S, et al. Astrocytes as determinants of disease progression in inherited amyotrophic lateral sclerosis. Nat Neurosci 2008;11:251-253.

69. Graeber MB. Changing face of microglia. Science 2010;330:783-788.

70. Ransohoff RM, Cardona AE. The myeloid cells of the central nervous system parenchyma. Nature 2010;468:253-262.

71. Davalos D, Grutzendler J, Yang G, et al. ATP mediates rapid microglial response to local brain injury in vivo. Nat Neurosci 2005;8:752-758.

72. Hanisch UK, Kettenmann H. Microglia: active sensor and versatile effector cells in the normal and pathologic brain. Nat Neurosci 2007;10:1387-1394.

73. Nimmerjahn A, Kirchhoff F, Helmchen F. Resting microglial cells are highly dynamic surveillants of brain parenchyma in vivo. Science 2005;308:1314-1318.

74. Beers DR, Henkel JS, Xiao Q, et al. Wild-type microglia extend survival in PU.1 knockout mice with familial amyotrophic lateral sclerosis. Proc Natl Acad Sci U S A 2006;103:16021-16026.

75. Priller J, Flugel A, Wehner T, et al. Targeting gene-modified hematopoietic cells to the central nervous system: use of green fluorescent protein uncovers microglial engraftment. Nat Med 2001;7:1356-1361.

76. Corti S, Locatelli F, Donadoni C, et al. Wild-type bone marrow cells ameliorate the phenotype of SOD1-G93A ALS mice and contribute to CNS, heart and skeletal muscle tissues. Brain 2004;127:2518-2532.

77. Ohnishi S, Ito $\mathrm{H}$, Suzuki $\mathrm{Y}$, et al. Intra-bone marrow-bone marrow transplantation slows disease progression and prolongs survival in G93A mutant SOD1 transgenic mice, an animal model mouse for amyotrophic lateral sclerosis. Brain Res 2009;1296:216-224.

78. Corti S, Nizzardo M, Nardini M, et al. Systemic transplantation of c-kit+cells exerts a therapeutic effect in a model of amyotrophic lateral sclerosis. Human Mol Genet 2010;19:3782-3796. 
79. Kang J, Rivest S. MyD88-deficient bone marrow cells accelerate onset and reduce survival in a mouse model of amyotrophic lateral sclerosis. J Cell Biol 2007;179:1219-1230.

80. Lewis CA, Solomon JN, Rossi FM, Krieger C. Bone marrowderived cells in the central nervous system of a mouse model of amyotrophic lateral sclerosis are associated with blood vessels and express CX(3)CR1. Glia 2009;57:1410-1419.

81. Solomon JN, Lewis CA, Ajami B, Corbel SY, Rossi FM, Krieger C. Origin and distribution of bone marrow-derived cells in the central nervous system in a mouse model of amyotrophic lateral sclerosis. Glia 2006;53:744-753.

82. Chen R, Ende N. The potential for the use of mononuclear cells from human umbilical cord blood in the treatment of amyotrophic lateral sclerosis in SOD1 mice. J Med 2000;31:21-30.

83. Ende N, Weinstein F, Chen R, Ende M. Human umbilical cord blood effect on sod mice (amyotrophic lateral sclerosis). Life Sci 2000;67:53-59.

84. Appel SH, Engelhardt JI, Henkel JS, et al. Hematopoietic stem cell transplantation in patients with sporadic amyotrophic lateral sclerosis. Neurology 2008;71:1326-1334.

85. Deans RJ, Moseley AB. Mesenchymal stem cells: biology and potential clinical uses. Exp Hematol 2000;28:875-884.

86. Pittenger MF, Mackay AM, Beck SC, et al. Multilineage potential of adult human mesenchymal stem cells. Science 1999;284:143-147.

87. Prockop DJ. Marrow stromal cells as stem cells for nonhematopoietic tissues. Science 1997;276:71-74.

88. Joyce N, Annett G, Wirthlin L, Olson S, Bauer G, Nolta JA. Mesenchymal stem cells for the treatment of neurodegenerative disease. Regen Med 2010;5:933-946.

89. Sadan O, Melamed E, Offen D. Bone-marrow-derived mesenchymal stem cell therapy for neurodegenerative diseases. Expert Opin Biol Ther 2009;9:1487-1497.

90. Scuteri A, Ravasi M, Pasini S, Bossi M, Tredici G. Mesenchymal stem cells support dorsal root ganglion neurons survival by inhibiting the metalloproteinase pathway. Neuroscience 2011;172:12-19.

91. Wislet-Gendebien S, Hans G, Leprince P, Rigo JM, Moonen G, Rogister B. Plasticity of cultured mesenchymal stem cells: switch from nestin-positive to excitable neuron-like phenotype. Stem cells (Dayton, Ohio) 2005;23:392-402.

92. Wislet-Gendebien S, Wautier F, Leprince P, Rogister B. Astrocytic and neuronal fate of mesenchymal stem cells expressing nestin. Brain Res Bull 2005;68:95-102.

93. Boucherie C, Schafer S, Lavand'homme P, Maloteaux JM, Hermans E. Chimerization of astroglial population in the lumbar spinal cord after mesenchymal stem cell transplantation prolongs survival in a rat model of amyotrophic lateral sclerosis. J Neurosci Res 2009;87:2034-2046.

94. Kim H, Kim HY, Choi MR, et al. Dose-dependent efficacy of ALS-human mesenchymal stem cells transplantation into cisterna magna in SOD1-G93A ALS mice. Neurosci Lett 2010;468: 190-194.

95. Zhang C, Zhou C, Teng JJ, Zhao RL, Song YQ, Zhang C. Multiple administrations of human marrow stromal cells through cerebrospinal fluid prolong survival in a transgenic mouse model of amyotrophic lateral sclerosis. Cytotherapy 2009;11:299-306.

96. Zhao CP, Zhang C, Zhou SN, et al. Human mesenchymal stromal cells ameliorate the phenotype of SOD1-G93A ALS mice. Cytotherapy 2007;9:414-426.

97. Morita E, Watanabe $\mathrm{Y}$, Ishimoto $\mathrm{M}$, et al. A novel cell transplantation protocol and its application to an ALS mouse model. Exp Neurol 2008;213:431-438.

98. Dadon-Nachum M, Sadan O, Srugo I, Melamed E, Offen D. Differentiated Mesenchymal Stem Cells for Sciatic Nerve Injury. Stem Cell Rev 2011;7(3):664-671.
99. Mazzini L, Ferrero I, Luparello V, et al. Mesenchymal stem cell transplantation in amyotrophic lateral sclerosis: a phase I clinical trial. Exp Neurol 2010;223:229-237.

100. Mazzini L, Fagioli F, Boccaletti R, et al. Stem cell therapy in amyotrophic lateral sclerosis: a methodological approach in humans. Amyotroph Lateral Scler Other Motor Neuron Disord 2003;4:158-161.

101. Vercelli A, Mereuta OM, Garbossa D, et al. Human mesenchymal stem cell transplantation extends survival, improves motor performance and decreases neuroinflammation in mouse model of amyotrophic lateral sclerosis. Neurobiol Dis 2008;31:395-405.

102. Guillemain I, Alonso G, Patey G, Privat A, Chaudieu I. Human NT2 neurons express a large variety of neurotransmission phenotypes in vitro. J Comp Neurol 2000;422:380-395.

103. Pleasure SJ, Lee VM. NTera 2 cells: a human cell line which displays characteristics expected of a human committed neuronal progenitor cell. J Neurosci Res 1993;35:585-602.

104. Fijak M, Bhushan S, Meinhardt A. Immunoprivileged sites: the testis. Methods Mol Biol 2011;677:459-470.

105. Raibon E, Todd LM, Moller T. Glial cells in ALS: the missing link? Phys Med Rehab Clin N Am 2008;19:441-459.

106. Kimelberg HK, Nedergaard M. Functions of astrocytes and their potential as therapeutic targets. Neurotherapeutics 2010;7:338-353.

107. Lepore AC, Rauck B, Dejea C, et al. Focal transplantation-based astrocyte replacement is neuroprotective in a model of motor neuron disease. Nat Neurosci 2008;11:1294-1301.

108. Rao MS. Multipotent and restricted precursors in the central nervous system. The Anat Rec 1999;257:137-148.

109. Svendsen CN, Clarke DJ, Rosser AE, Dunnett SB. Survival and differentiation of rat and human epidermal growth factorresponsive precursor cells following grafting into the lesioned adult central nervous system. Exp Neurol 1996;137:376-388.

110. Svendsen CN, Caldwell MA, Shen J, et al. Long-term survival of human central nervous system progenitor cells transplanted into a rat model of Parkinson's disease. Exp Neurol 1997;148:135-146.

111. Kim HJ, McMillan E, Han F, Svendsen CN. Regionally specified human neural progenitor cells derived from the mesencephalon and forebrain undergo increased neurogenesis following overexpression of ASCL1. Stem Cells 2009;27:390-398.

112. Wright LS, Li J, Caldwell MA, Wallace K, Johnson JA, Svendsen CN. Gene expression in human neural stem cells: effects of leukemia inhibitory factor. J Neurochem 2003;86:179-195.

113. Ostenfeld T, Caldwell MA, Prowse KR, Linskens MH, Jauniaux E, Svendsen CN. Human neural precursor cells express low levels of telomerase in vitro and show diminishing cell proliferation with extensive axonal outgrowth following transplantation. Exp Neurol 2000;164:215-226.

114. Wright LS, Prowse KR, Wallace K, Linskens MH, Svendsen CN. Human progenitor cells isolated from the developing cortex undergo decreased neurogenesis and eventual senescence following expansion in vitro. Exp Cell Res 2006;312:2107-2120.

115. Ostenfeld T, Joly E, Tai YT, et al. Regional specification of rodent and human neurospheres. Brain Res Dev Brain Res 2002;134:43-55.

116. Johe KK, Hazel TG, Muller T, Dugich-Djordjevic MM, McKay $\mathrm{RD}$. Single factors direct the differentiation of stem cells from the fetal and adult central nervous system. Genes Dev 1996;10:3129-3140.

117. Xu L, Ryugo DK, Pongstaporn T, Johe K, Koliatsos VE. Human neural stem cell grafts in the spinal cord of SOD1 transgenic rats: differentiation and structural integration into the segmental motor circuitry. J Comp Neurol 2009;514:297-309.

118. Xu L, Shen P, Hazel T, Johe K, Koliatsos VE. Dual transplantation of human neural stem cells into cervical and lumbar cord 
ameliorates motor neuron disease in SOD1 transgenic rats. Neurosci Lett 2011;494(3):222-226.

119. Xu L, Yan J, Chen D, et al. Human neural stem cell grafts ameliorate motor neuron disease in SOD-1 transgenic rats. Transplantation 2006;82:865-875.

120. Yan J, Xu L, Welsh AM, et al. Combined immunosuppressive agents or CD4 antibodies prolong survival of human neural stem cell grafts and improve disease outcomes in amyotrophic lateral sclerosis transgenic mice. Stem Cells 2006;24:1976-1985.

121. Yan J, Xu L, Welsh AM, et al. Extensive neuronal differentiation of human neural stem cell grafts in adult rat spinal cord. PLoS Med 2007;4:e39.

122. Lunn JS, Sakowski SA, Federici T, Glass JD, Boulis NM, Feldman EL. Stem cell technology for the study and treatment of motor neuron diseases. Regen Med 2011;6:201-213.

123. Henriques A, Pitzer C, Schneider A. Neurotrophic growth factors for the treatment of amyotrophic lateral sclerosis: where do we stand? Front Neurosci 2010;4:32.

124. Alisky JM, Davidson BL. Gene therapy for amyotrophic lateral sclerosis and other motor neuron diseases. Hum Gene Ther 2000;11:2315-2329.

125. Miller RG, Petajan JH, Bryan WW, et al. A placebo-controlled trial of recombinant human ciliary neurotrophic (rhCNTF) factor in amyotrophic lateral sclerosis. rhCNTF ALS Study Group. Ann Neurol 1996;39:256-260

126. Borasio GD, Robberecht W, Leigh PN, et al. A placebocontrolled trial of insulin-like growth factor-I in amyotrophic lateral sclerosis. European ALS/IGF-I Study Group. Neurology 1998;51:583-586.

127. Park S, Kim HT, Yun S, et al. Growth factor-expressing human neural progenitor cell grafts protect motor neurons but do not ameliorate motor performance and survival in ALS mice. Exp Mol Med 2009;41:487-500.

128. Kordower JH, Palfi S, Chen EY, et al. Clinicopathological findings following intraventricular glial-derived neurotrophic factor treatment in a patient with Parkinson's disease. Ann Neurol 1999;46:419-424.

129. Nutt JG, Burchiel KJ, Comella CL, et al. Randomized, doubleblind trial of glial cell line-derived neurotrophic factor (GDNF) in PD. Neurology 2003;60:69-73.

130. Hwang DH, Lee HJ, Park IH, et al. Intrathecal transplantation of human neural stem cells overexpressing VEGF provide behavioral improvement, disease onset delay and survival extension in transgenic ALS mice. Gene Ther 2009;16:1234-1244.

131. Mohajeri MH, Figlewicz DA, Bohn MC. Intramuscular grafts of myoblasts genetically modified to secrete glial cell line-derived neurotrophic factor prevent motoneuron loss and disease progression in a mouse model of familial amyotrophic lateral sclerosis. Human gene therapy 1999;10:1853-1866.

132. Suzuki M, McHugh J, Tork C, et al. Direct muscle delivery of GDNF with human mesenchymal stem cells improves motor neuron survival and function in a rat model of familial ALS. Mol Ther 2008; 16:2002-2010.

133. Takahashi K, Yamanaka S. Induction of pluripotent stem cells from mouse embryonic and adult fibroblast cultures by defined factors. Cell 2006;126:663-676.

134. Yu J, Vodyanik MA, Smuga-Otto K, et al. Induced pluripotent stem cell lines derived from human somatic cells. Science 2007;318:1917-1920.

135. Takahashi K, Tanabe K, Ohnuki M, et al. Induction of pluripotent stem cells from adult human fibroblasts by defined factors. Cell 2007;131:861-872.

136. Park IH, Zhao R, West JA, et al. Reprogramming of human somatic cells to pluripotency with defined factors. Nature 2008;451:141-146.
137. Mattis VB, Svendsen CN. Induced pluripotent stem cells: a new revolution for clinical neurology? Lancet Neurol 2011;10:383-394

138. Vaziri H, Chapman KB, Guigova A, et al. Spontaneous reversal of the developmental aging of normal human cells following transcriptional reprogramming. Regen Med 2010;5:345-363.

139. Jaarsma D, Teuling E, Haasdijk ED, De Zeeuw CI, Hoogenraad CC. Neuron-specific expression of mutant superoxide dismutase is sufficient to induce amyotrophic lateral sclerosis in transgenic mice. J Neurosci 2008;28:2075-2088.

140. Inoue H, Yamanaka S. The Use of Induced Pluripotent Stem Cells in Drug Development. Clini Pharmacol Ther 2010;89(5):655-661.

141. Zhao T, Zhang ZN, Rong Z, Xu Y. Immunogenicity of induced pluripotent stem cells. Nature 2011;474:212-215.

142. Tamaoki N, Takahashi K, Tanaka T, et al. Dental pulp cells for induced pluripotent stem cell banking. J Dent Res 2010;89:773-778.

143. Alipio Z, Liao W, Roemer EJ, et al. Reversal of hyperglycemia in diabetic mouse models using induced-pluripotent stem (iPS)derived pancreatic beta-like cells. Proc Natl Acad Sci U S A 2010;107:13426-13431.

144. Hanna J, Wernig M, Markoulaki S, et al. Treatment of sickle cell anemia mouse model with iPS cells generated from autologous skin. Science 2007;318:1920-1923.

145. Tsuji O, Miura K, Okada Y, et al. Therapeutic potential of appropriately evaluated safe-induced pluripotent stem cells for spinal cord injury. Proc Natl Acad Sci U S A 2010;107:12704-12709.

146. Wernig M, Zhao JP, Pruszak J, et al. Neurons derived from reprogrammed fibroblasts functionally integrate into the fetal brain and improve symptoms of rats with Parkinson's disease. Proc Natl Acad Sci U S A 2008;105:5856-5861.

147. Xu D, Alipio Z, Fink LM, et al. Phenotypic correction of murine hemophilia A using an iPS cell-based therapy. Proc Natl Acad Sci U S A 2009;106:808-813.

148. Darabi R, Pan W, Bosnakovski D, Baik J, Kyba M, Perlingeiro RC. Functional Myogenic Engraftment from Mouse iPS Cells. Stem cell reviews 2011

149. Lindvall O, Kokaia Z. Stem cells in human neurodegenerative disorders-time for clinical translation? J Clin Invest 2010;120:29-40.

150. endsen CN, Langston JW. Stem cells for Parkinson disease and ALS: replacement or protection? Nat Med 2004;10:224-225.

151. Federici T, Riley J, Park J, Bain M, Boulis N. Preclinical safety validation of a stabilized viral vector direct injection approach to the cervical spinal cord. Clin Transl Sci 2009;2:165-167.

152. Raore B, Federici T, Taub J, et al. Cervical multilevel intraspinal stem cell therapy: assessment of surgical risks in Gottingen minipigs. Spine 2011;36:E164-E171.

153. Riley J, Federici T, Park J, et al. Cervical spinal cord therapeutics delivery: preclinical safety validation of a stabilized microinjection platform. Neurosurgery 2009;65:754-762.

154. Ozdinler PH, Benn S, Yamamoto TH, Guzel M, Brown RH Jr, Macklis JD. Corticospinal Motor neurons and related subcerebral projection neurons undergo early and specific neurodegeneration in hSOD1G93A transgenic ALS mice. J Neurosci 2011;31:4166-4177.

155. Zang DW, Cheema SS. Degeneration of corticospinal and bulbospinal systems in the superoxide dismutase $1(\mathrm{G} 93 \mathrm{~A} \mathrm{G} 1 \mathrm{H})$ transgenic mouse model of familial amyotrophic lateral sclerosis. Neurosci Lett 2002;332:99-102.

156. Su H, Zhang W, Guo J, Guo A, Yuan Q, Wu W. Neural progenitor cells enhance the survival and axonal regeneration of injured motoneurons after transplantation into the avulsed ventral horn of adult rats. J Neurotrauma 2009;26:67-80.

157. Mitrecic D, Nicaise C, Gajovic S, Pochet R. Distribution, differentiation, and survival of intravenously administered neural stem cells in a rat model of amyotrophic lateral sclerosis. Cell Transplant 2010;19:537-548. 